\title{
POINT PREVALENCE SURVEY OF ANTIBIOTIC USE AND RESISTANCE AT A REFERRAL HOSPITAL IN KENYA; FINDINGS AND IMPLICATIONS
}

\author{
Caleb Okotha, Sylvia Opangaa ${ }^{a}$, Faith Okalebo ${ }^{b}, M^{2}$ argaret Oluka ${ }^{b}$, Amanj Baker Kurdic, Brian Godman ${ }^{\mathrm{c}, \mathrm{d}, \mathrm{e}^{*}}$ \\ aDepartment of Pharmaceutics and Pharmacy practice, School of Pharmacy, University of Nairobi, Kenya. \\ Email: okothcaleb@yahoo.com; sopanga@uonbi.ac.ke \\ bDepartment of Pharmacology and Pharmacognosy, School of Pharmacy, University of Nairobi, Kenya. \\ Email: okalebof@yahoo.com; margaretoluka0@gmail.com \\ 'Strathclyde Institute of Pharmacy and Biomedical Sciences, Strathclyde University, Glasgow UK. Emails: \\ amani.baker@strath.ac.uk; brian.godman@strath.ac.uk \\ dDivision of Clinical Pharmacology, Karolinska Institutet, Stockholm, Sweden. Email: brian.godman@ki.se \\ eHealth Economics Centre, Liverpool University Management School, Liverpool University, UK. Email: \\ Brian.Godman@liverpool.ac.uk \\ ${ }^{*}$ Corresponding author: Brian Godman, Strathclyde Institute of Pharmacy and Biomedical Sciences, \\ University of Strathclyde, Glasgow G4 ORE, United Kingdom. Email: Brian.godman@strath.ac.uk. \\ (Accepted for publication in Hospital Practice - Please keep Confidential)
}

Abstract

Background and aims: A substantial amount of antibiotic use in hospitals may be inappropriate, potentially leading to the development and spread of antibiotic resistance, adverse effects, mortality and increased hospital costs. The objective was to assess current patterns of antibiotic use in a leading referral hospital in Western Kenya. This would lead to the-identification of opportunities for quality improvement in this hospital and across Kenya. Methodology: A point prevalence survey was carried out with data abstracted principally from patient medical records supplemented by interviews from physicians when needed. The pattern of antibiotic use was analyzed by descriptive methods. Differences in antibiotic use and indications between the selected wards were compared using the Chi-square test or Fisher's exact tests. Results: Among the patients surveyed, $67.7 \%$ were on antibiotics. The most common classes of antibiotics prescribed were third generation cephalosporins (55\%), imidazole derivatives like metronidazole $(41.8 \%)$ and broad spectrum penicillins $(41.8 \%)$. The most common indication for antibiotic use was medical prophylaxis (29\%), with local guidelines advocating antibiotic prophylaxis in mothers after delivery of their child as well as in neonates with birth asphyxia and low weight at birth. Dosing of antibiotics was seen as generally optimal when assessed against current recommendations. Conclusion: Whilst the dosing of antibiotics seemed adequate, there was high use of antibiotics in this hospital. This needs to be urgently reviewed with current appreciable empiric antibiotic use. Programmes are being instigated to address these concerns including developing antibiotic guidelines and formularies especially for empiric use as well as implementing antimicrobial stewardship activities.

\section{INTRODUCTION}

Antibiotics are indispensable part of modern medicines and the cornerstone for treating bacterial infections across healthcare sectors [1-5]. They are now one of the most common medicines prescribed in hospitals and across sectors $[1,6,7]$ to reduce morbidity and mortality $[1,2,7,8]$. However, there are concerns with their overuse, increasing resistance rates as well as increasing morbidity, mortality and costs [2,9-13]. Previous studies in Kenya have found a high prevalence of inpatient antibiotic use at $81.7 \%$ [14] and outpatient use at $68.0 \%$ to $72.9 \%$ of patients [14, 15]. Among 18 hospitals in Egypt, the prevalence of antibiotic use was $59 \%$ among in-patients [16], and in Nigeria $55.9 \%$ of in-patients patients were prescribed antibiotics [8]. In China, the prevalence of antibiotic use among in-patients was $56 \%$ in a recent study [17]. As a result, there is a growing urgency for countries to develop their own action plans to improve future antibiotic use, including proactive antibiotic surveillance programs especially in low and middle income countries (LMICs), driven by the World Health Organisation and others [8,18-24]. This is because a substantial proportion of antibiotics in hospitals may be inappropriate, based on factors such 
as a lack of any indication or incorrect selection, wrong dosing levels, inappropriate treatment duration or multiple prescribing $[8,25,26]$. Overall, only around $60 \%$ of empirically started antibiotics are considered appropriate [27].Escherichia coli, Staphylococcus aureus and Klebsiella pneumonia are the three organisms of greatest concern associated with both community and hospital acquired infections[28], with more recently Pseudomonas aeruginosa, carbapenem-resistant and third-generation cephalosporinresistant enterobacteriaceae and meticillin-resistant Staphylococcus aureus a concern [29]. Resistance to Klebsiella pneumonia has also been seen in Kenya [30], Concerns with increasing resistance rates necessitates urgent action; however, hampered by issues of capacity to undertake sensitivity testing and barriers to routine testing [31]. High rates of antibiotic resistance are also seen across Africa, the Middle East and Asia, with an appreciable number of $\mathrm{WHO}$ regions now reporting high resistance rates leading to increased prescribing of second and third line antibiotics [7,32].

Adherence to agreed national guidelines should help improve future antibiotic use and reduce resistance rates $[7,33,34]$. However, there are concerns with current adherence to recommended antibiotic treatments and doses for infectious diseases across countries [27, 33-35] although not universal [36], as well as a lack of formularies and associated activities in hospitals in Africa to improve future antibiotic use [37-39]. In Kenya, currently only 4 in 10 public hospitals were complying with the National treatment guidelines when their prescribing was analyzed raising concerns with increasing AMR rates [40]. Despite these concerns, there is currently a lack of overall data on antibiotic use e among hospitals in Kenya especially Western Kenya. This data is important to help develop pertinent strategies to improve the future use of antibiotics in hospitals as part of the National Action Plan on Antibiotic use of Kenya [21], especially given the high prevalence of infectious diseases in Western Kenya including HIV [41].

Consequently as a first step, we sought to conduct a point prevalence survey to quantify antimicrobial utilization at Jaramogi Oginga Odinga Teaching and Referral Hospital in the Western region of Kenya. It is hoped that this information will serve as a baseline for future point-prevalence surveys in Kenya, as well as provide a baseline for developing appropriate antimicrobial stewardship programs and interventions in this part of Kenya and wider including guidelines for the empiric use of antibiotics.

\section{METHODOLOGY}

\subsection{Study setting}

The study was carried out at Jaramogi Oginga Odinga Teaching and Referral Hospital (JOOTRH), which is the major referral Hospital in Western Kenya, serving a population in excess of 5 million. The hospital is located 3.5 miles from the city centre of Kisumu. The hospital has a bed capacity of 467 with bed occupancy of $94.8 \%$.

\subsection{Study design and target population}

A point prevalence cross-sectional design was employed to determine the variation and characterize the current use of antibiotics in sampled departments in JOOTRH. The Global point prevalence survey protocol [42] provided a basis for the forms that were adopted to subsequently evaluate antimicrobial prescribing practices in JOOTRH and identify targets for quality improvement. This builds on a similar situation for point prevalence studies now being undertaken in Botswana, South Africa and Zimbabwe [43-46].

The target population included adult, paediatric, male and female inpatients on antibiotics admitted at JOOTRH, with data collection taking place between $5^{\text {th }}$ to $12^{\text {th }}$ June 2017.

\subsection{Sampling and eligibility criteria}

Universal sampling was used to select patients. The global PPS method of data collection for patients present in the wards was principally applied in the paediatric, surgical, intensive care and newborn units. In these departments, patient prescriptions and files were accessed at $2.00 \mathrm{pm}$. This timing for the survey was selected so as to minimize interruption of ward rounds which usually take place in the morning hours. However, information about the targeted hospital wards was collected at 8.00 am on the day of survey since this timing did not interrupt ward rounds. Due to external factors that were unavoidable including an ongoing nurses strike, minor modifications of the Global PPS methodology were made to facilitate data collection in medical, gynaecology and postnatal wards, with many patients being discharged from these 
wards during data collection. Consequently in this instance, files for patients the day before the survey were located using the occurrence book and retrieved from the wards and health records department. An assumption was made that patients were present in these wards at the time of survey to obtain a better picture of current antibiotic use.

Medical records were included if the patient was on any antibiotic at the time of the study, admitted to sampled wards at JOOTRH, of any age and sex or had complete records. Records were excluded if the patient was an outpatient, was seeking treatment outside JOOTRH or their records were missing.

\subsection{Data collection}

Data was collected using two standardized forms adopted from Global point prevalence survey protocol. One form collected data about the hospital wards (date of survey, patient population, ward type and number of patients on each ward on the day of the survey). The second form was used to collect data about each patient included in the survey, i.e. patient demographic characteristics, name of the antibiotics prescribed, single unit dose, route, frequency, duration of use, diagnosis and indications. The total daily prescribed dose was computed as the product of single unit doses and frequency rather than using approaches such as defined daily doses (DDDs).

Two research assistants were recruited to help with data collection. These were clinical officers on internships stationed on the wards and trained in data collection. Clinical officers are medical practitioners who hold a diploma in clinical medicine, typically referred to as medical assistants in other countries.

\subsubsection{Data source}

The principal source for completing data collection was through a review of the patient's medical records. The treating physician was interviewed if needed for clarification. However, this only happened in a minority of situations (10 patient files in total: 3 in the newborn unit, 3 in the surgical ward and 4 in the pediatric ward).

\subsubsection{Antibiotic usage definitions}

The indications for the antibiotics prescribed were either therapeutic or for prevention (prophylaxis). Infections were further divided into community acquired infection and hospital acquired infections. Infections were considered as community acquired if symptoms started $<48$ hours from admission to hospital (or present on admission), and hospital acquired if symptoms start 48 hours after admission to hospital based on chart review. This could include post-operative surgical site infections (within 30 days of surgery or 1 year after implant surgery), hospital acquired pneumonia, and Clostridium difficile associated diarrhoea ( $>48$ hours post admission or $<30$ days after discharge from previous admission episode).

Preventive use, also termed prophylaxis, was further divided into medical or surgical prophylaxis. Medical prophylaxis was documented when antibiotics were prescribed to prevent infections in patients with medical conditions, e.g. prophylaxis for meningococcal infections, respiratory infections and endocarditis, prophylaxis in neutropenic patients or prophylaxis for maternal risk factors. In addition, cotrimoxazole in patients with HIV and their long term use to prevent opportunistic infections such as Pneumocystis jeruvecii pneumonia. Surgical prophylaxis includes the use of antibiotics to prevent infections at surgical sites, with the anatomical site referring to the organ system in which the infection has been identified or for prophylactic use.

\subsubsection{Prescribing and dispensing of medicines}

Medicines for the hospital are obtained from the Kenya Medical supply agency (KEMSA) and local suppliers. For inpatients, treatment sheets are used to obtain prescribed medicines from the Pharmacy. The treatment sheets, which lists all medicines patients were taking whilst in hospital, were used to collect antibiotic prescription data. The billing of the costs of medicines is undertaken when they are issued, with patients required to pay for their medicines and bed charges during discharge.

At time of the study, the hospital did not have a formulary. In addition, there were variable national guidelines available as well as some local guidelines such as guidelines for paediatrics, surgery and 
obstetrics and gynaecology; however, they typically did not contain maximum daily doses for all potential antibiotics and indications for the study. Consequently, we used the UK British National Formulary (https://www.bnf.org/) to assess the quality of prescribed doses, i.e. to ascertain whether these were optimal in line with recommendations from the BNF. The BNF was selected over other possible prescribing guidance sources because it was readily available online, and as paper copies and mobile applications. Secondly, it is designed as a digest for rapid reference and is easy and convenient to use. In addition, the BNF is currently available to pharmacists in Kenya for free via the Pharmaceutical Society of Kenya.

The local gynecological guidelines recommend the use of antibiotics for prophylaxis in mothers after delivery [47-49]. Basic paediatric protocols in Kenya also recommend antibiotic prophylaxis in neonates with birth asphyxia and low body weight at birth [48]. Local guidelines also advocate the use of third generation cephalosporins such as ceftriaxone as second line management of community acquired infections such as pneumonia and meningitis. There are also local guidelines for surgical prophylaxis but these are not considered adequate and are currently being updated.

\subsection{Variables}

Because the study was mainly descriptive and aimed to study patterns of antibiotic use, the following indicators were key outcome measures of interest:

- Percentage of use of any antibiotic in the entire hospital and in the different wards.

- Percentage of use of the various types of antibiotics in the entire hospital and various wards.

- The number of antibiotics prescribed for each patient.

- Prevalence of prescribing according to local guidelines where they exist.

- Irrational prescribing, defined as the wrong dose

- Prevalence of empiric antibiotic use as depicted by the frequency of requesting for sensitivity analyses

\subsection{Statistical analysis}

Statistical analysis was conducted using Stata version software 13. Categorical data was summarized as counts and percentages. Differences in antibiotic use and indications between the wards were compared using Chi-square test or Fisher's exact tests. .

\subsection{Ethical considerations}

Approval to carry out the research was obtained from Kenyatta National Hospital/University of Nairobi Ethics and Research committee in May 2017 (letter Ref No. KNH-ERC/A/155) and Jaramogi Oginga Odinga Teaching and Referral Hospital Research and Training Committee in June 2017 (approval letter Ref No. ERC.1B/VOL.1/339).

\section{RESULTS}

The sampled departments had a total of 414 beds. The surgical ward had the highest number of beds $(26.6 \%, n=110)$, followed by medical ward $(23.9 \%, n=99)$. The sampled wards had total bed occupancy of $65 \%$. Most of the participants were aged between $20-64$ years $(58.2 \%, n=106)$, with a mean age of 26.9 years. More than half of the participants were female (62.1\%) (Table 1).

Table 1: Baseline characteristics of participants on antibiotics at Jaramogi Oginga Odinga Teaching and Referral Hospital

\begin{tabular}{|l|l|l|}
\hline Characteristic & & $\mathbf{n}(\%)$ \\
\hline & $<5$ & $35(19.2)$ \\
& $5-12$ & $13(7.1)$ \\
Age (years) & $13-19$ & $14(7.7)$ \\
\hline
\end{tabular}




\begin{tabular}{|l|l|l|}
\hline & $20-64$ & $106(58.2)$ \\
& $>65$ & $14(7.7)$ \\
\hline Sex & Male & $69(37.9)$ \\
& Female & $113(62.1)$ \\
\hline \multirow{5}{*}{ Wards } & Medical & $36(19.8)$ \\
& Surgery & $52(28.6)$ \\
& Pediatrics & $27(14.8)$ \\
& Newborn unit & $10(5.5)$ \\
& ICU & $2(1.1)$ \\
& Gynecology & $18(9.9)$ \\
& Post-natal & $37(20.3)$ \\
\hline
\end{tabular}

On the days of the survey, there were 269 patients admitted in the hospital. A total of 182 patients $(67.7 \%)$ were receiving one or more antibiotics. The prevalence was highest in the post-natal ward $(92.5 \%, n=37)$ followed by the newborn unit, the intensive care unit, medical and gynecology wards (Table 2).

Table 2: Prevalence of antibiotic use in Jaramogi Oginga Odinga Teaching and Referral Hospital

\begin{tabular}{|l|c|c|c|}
\hline $\begin{array}{l}\text { Patient } \\
\text { characteristics }\end{array}$ & $\begin{array}{l}\text { Number } \\
\text { of patients } \\
\text { (n= 269) }\end{array}$ & $\begin{array}{l}\text { Patient on } \\
\text { antibiotics } \\
\text { (n= 182) }\end{array}$ & $\begin{array}{l}\text { Prevalence } \\
\text { (\%) }\end{array}$ \\
\hline Post-natal & 40 & 37 & 92.5 \\
Newborn unit & 12 & 10 & 83.3 \\
Intensive care unit & 3 & 2 & 66.7 \\
Medical & 56 & 36 & 64.3 \\
Gynecology & 28 & 18 & 64.3 \\
Surgical & 84 & 52 & 61.9 \\
Pediatrics & 46 & 27 & 58.7 \\
\hline Totals & $\mathbf{2 6 9}$ & $\mathbf{1 8 2}$ & $\mathbf{6 7 . 7}$ \\
\hline
\end{tabular}

The 182 treated patients received a total of 333 antibiotic drugs (an average of 1.8 per patient). $7.1 \%$ in this study had HIVIAIDS recorded in their notes.

Antibiotics were used either prophylactically or therapeutically. Prophylactic use was more common than for therapeutic use (Table 3). The most common anatomical site for prophylactic use was gynaecology $(35.1 \%)$, followed by no defined site and the central nervous system. In the case of non-anatomic sites, antibiotics were used for medical prophylaxis in general without targeting a specific site. 
Table 3: Distribution of antibiotic use by anatomic site

\begin{tabular}{|c|c|c|c|}
\hline \multicolumn{4}{|l|}{ Use of antibiotics } \\
\hline & $\begin{array}{l}\text { Total } \\
(n=194) \\
n(\%)\end{array}$ & $\begin{array}{l}\text { Prophylaxis } \\
(n=111) \\
n(\%)\end{array}$ & $\begin{array}{l}\text { Treatment } \\
(n=83) \\
n(\%)\end{array}$ \\
\hline \multicolumn{4}{|c|}{ Systems with the highest prevalence of use $(>10 \%)$} \\
\hline No defined site & $33(17.0)$ & $17(15.3)$ & $16(19.3)$ \\
\hline Gynecological & $42(21.7)$ & $39(35.1)$ & $3(3.6)$ \\
\hline Respiratory tract & $26(13.4)$ & $2(1.8)$ & $24(28.9)$ \\
\hline Central nervous system & $25(12.9)$ & $16(14.4)$ & $9(10.8)$ \\
\hline Skin, soft tissue, bone and joints & $21(10.8)$ & $9(9.8)$ & $12(14.5)$ \\
\hline Gastro-intestinal tract & $20(10.3)$ & $12(10.8)$ & $8(9.6)$ \\
\hline Neonatal & $12(6.2)$ & $10(9.0)$ & $2(2.4)$ \\
\hline \multicolumn{4}{|c|}{ Systems with the lowest prevalence of use $(<10 \%)$} \\
\hline Urinary tract & $8(4.1)$ & $2(1.8)$ & $6(7.2)$ \\
\hline Ear, nose and throat & $3(1.6)$ & $2(1.8)$ & $1(1.2)$ \\
\hline Eye & $2(1.0)$ & $1(0.9)$ & $1(1.2)$ \\
\hline Cardiovascular system & $2(1.0)$ & $1(0.9)$ & $1(1.2)$ \\
\hline
\end{tabular}

NB: The denominator refers to the total frequency of antibiotic use among all anatomic sites

Patients on antibiotic treatment were mainly diagnosed with respiratory tract infections $(28.9 \%)$ followed by no defined site of infection (19.3\%) and skin, soft tissues, bone and joints infections (14.5\%). The most common indication for antibiotic use was medical prophylaxis (29\%) (Figure 1). 
Figure 1: Distribution of patients on antibiotic treatment by indications

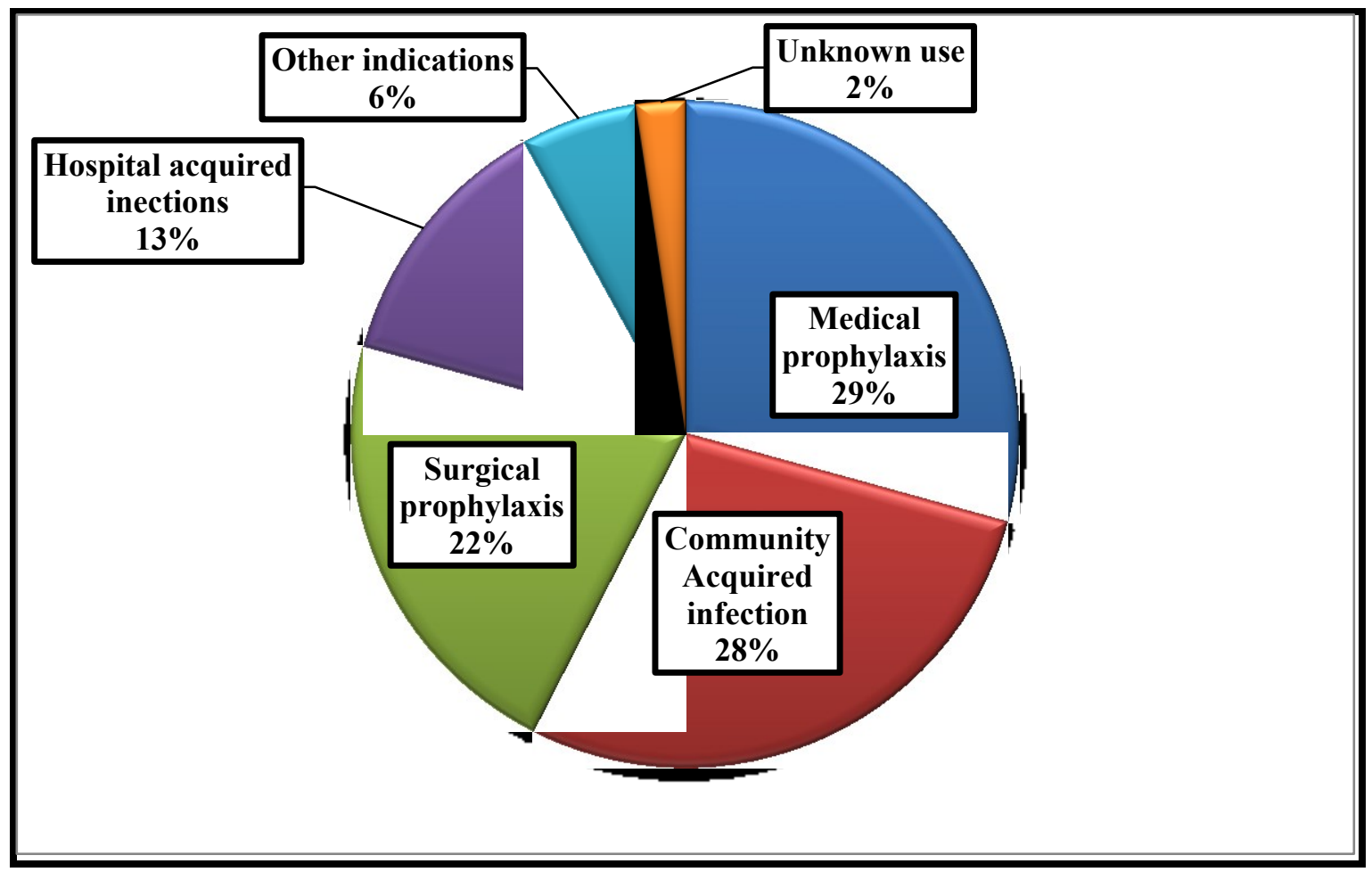

The relative frequency of each indication for antibiotic use varied among the different types of wards (Figure 2). The most common indication for antibiotic use among patients on the medical ward was for the treatment of community-acquired infection (55\%), whereas surgical prophylaxis was the most common indication for antibiotic use in the surgical wards (67.9\%). Medical prophylaxis was the main indication of antibiotic use in postnatal ward $(32.8 \%)$, with medical prophylaxis the only indication in the newborn unit $(100 \%)$. Fewer than $70 \%$ of patients in the surgical ward were prescribed antibiotics for surgical prophylaxis. The average number of antibiotic doses for surgical prophylaxis was 19.1 
Figure 2: Distribution of patients on antibiotics treatment by indication stratified by hospital wards

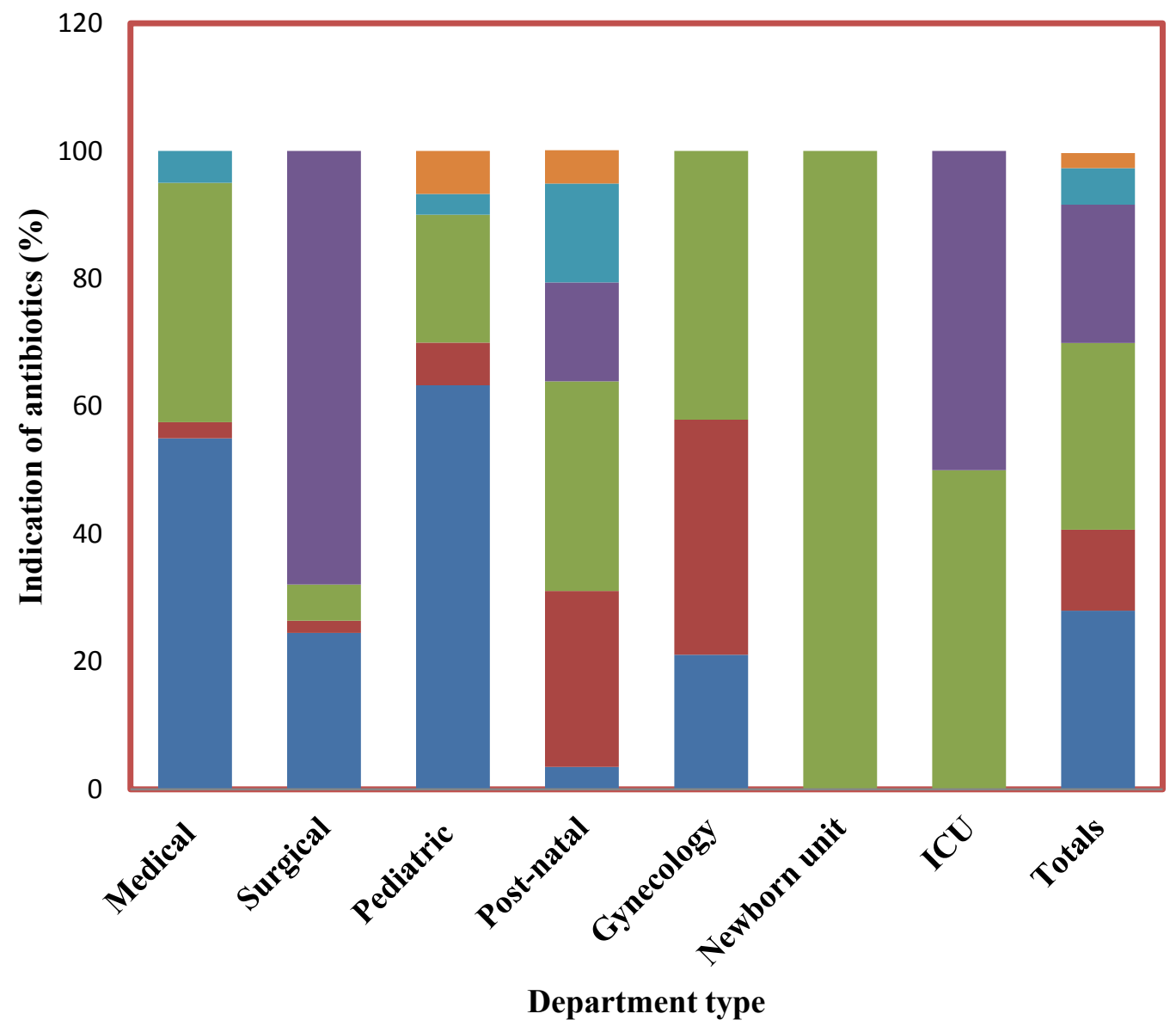

\begin{tabular}{|ll|}
\hline Community acquired infections & Hospital associated infections \\
Medical prophylaxis & Surgical prophylaxis \\
Other indications & Completely unknown indications \\
\hline
\end{tabular}

Antibiotics with a high frequency of use were third generation cephalosporins (55\%), imidazole derivatives (41.8\%), broad-spectrum penicillins (41.8\%) and aminoglycosides (7.1\%) (Figure 3). The prescribing of third generation cephalosporins was appreciably higher in the pediatric ward compared with other antibiotics $(92.6 \%$ of total use, $p<0.01)$ and lower in the newborn unit $(10 \%, p<0.0 .1)$ versus other antibiotics. There was relatively high use of third generation cephalosporins in the surgical wards $(55 \%$ of the total number of surgical patients on antibiotics; $n=29)$ ). The majority of antibiotics prescribed in the postnatal ward were imidazole derivatives including metronidazole $(86.5 \%, p<0.01)$, attributed to a high frequency of mixed anaerobic and aerobic infections in this setting, as well as broad spectrum penicillins $(81.1 \%, p<0.01)$. Aminoglycoside use was mainly in the newborn unit $(80 \%, p<0.01)$. 
Figure 3: Distribution of high frequency use antibiotics across the wards (some participants received more than one antibiotic)

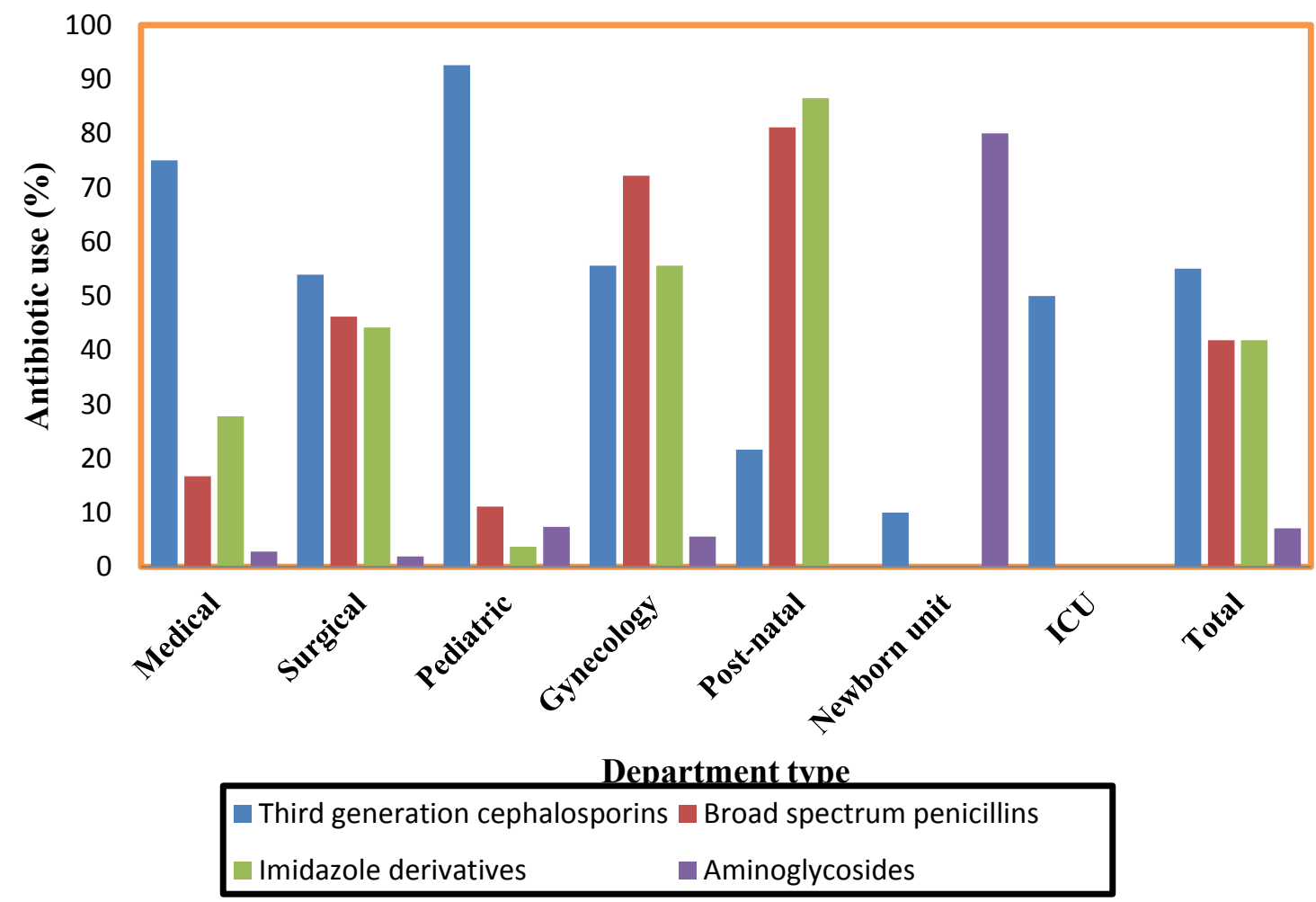

The total prescribed daily doses of the all most frequently prescribed oral antibiotics were found to be optimal when compared to daily doses recommended by United Kingdom British National Formulary (UK BNF). The prescribed daily dose of ceftriaxone was higher than maximum daily dose recommended by UK BNF at $6000 \mathrm{mg}$. The other parenteral antibiotics including benzyl penicillin (4800 $\mathrm{mg})$, flucloxacillin $(4000 \mathrm{mg})$, gentamicin $(390 \mathrm{mg})$, metronidazole $(1500 \mathrm{mg})$, co-amoxiclav $(2400 \mathrm{mg})$, meropenem $(1500 \mathrm{mg})$ and ceftazidime $(900 \mathrm{mg})$ had normal daily doses when compared to those recommended by the UK BNF. Most of the antibiotics were prescribed three times a day (37.2\%) followed by twice a day (27.9\%) as shown in Table 4. However, $1.5 \%$ of prescriptions had no frequency indicated. The most common route of administration was intravenous (63.1\%), with the oral route accounting for $32.4 \%$ of use. The most frequent duration of use was between $5-7$ days (73.6\%) followed by 1 to 4 days (13.8\%). $5.7 \%$ of prescriptions had no duration indicated.

Table 4: Frequency, route of administration and duration of antibiotic use

\begin{tabular}{|l|c|c|}
\hline Variable & Parameters & $\mathbf{n}(\%)$ \\
\hline \multirow{4}{*}{ Frequency } & Not indicated & $5(1.5)$ \\
\cline { 2 - 3 } & STAT & $14(4.2)$ \\
\cline { 2 - 3 } & Once daily & $65(19.5)$ \\
\cline { 2 - 3 } & Twice daily & $93(27.9)$ \\
\cline { 2 - 3 } & Three times a day & $124(37.2)$ \\
\cline { 2 - 3 } & Four times a day & $32(9.6)$ \\
\cline { 2 - 3 } & Not indicated & $3(0.9)$ \\
\hline
\end{tabular}




\begin{tabular}{|l|c|c|}
\hline \multirow{3}{*}{ Route } & Oral & $108(32.4)$ \\
\cline { 2 - 3 } & Intravenous & $210(63.1)$ \\
\cline { 2 - 3 } & Intramuscular & $9(2.7)$ \\
\cline { 2 - 3 } & Topical & $3(0.9)$ \\
\hline \multirow{2}{*}{ Duration of use (days) } & Not indicated & $19(5.7)$ \\
\hline
\end{tabular}

\section{DISCUSSION}

$67.7 \%$ of patients admitted at JOOTRH were on antibiotics, similar to a previous study undertaken in Kenya among inpatients in Kenya [14] This may suggest over prescribing of antibiotics, compared to several studies in Europe which report the prevalence of antibiotic use in hospitals between 25-35\%. [5053]. The differences may be due to well developed antimicrobial stewardship programmes in Europe. However, this needs to be investigated further before any definitive statements can be made, given the high prevalence of infectious diseases in sub-Sahara Africa including HIV as well as multi-drug resistant organisms [33,37,41,54]. As mentioned, $7.1 \%$ of patients had HIV/ AIDS. However, this is likely to be an under-estimate as patients may be unwilling to divulge their status similar to other studies in Africa [45]. The most common indication for antibiotic use was medical prophylaxis, followed by community acquired infections, surgical prophylaxis and hospital acquired infections (Figure 2). This is different from other studies conducted among European hospitals that showed community acquired infections were the most common indication for antibiotic use [51-52]. This may indicate prophylactic treatment for patients with or suspected to have HIVI AIDS. In addition, high prophylactic use of broad spectrum penicillins and imidazole derivatives in the postnatal ward is in accordance with local gynecological guidelines recommending antibiotics for prophylaxis in mothers after delivery [47]. Similarly, a high use of antibiotic prophylaxis in neonates is in line with guidelines in neonates with birth asphyxia and low body weight at birth [48].

Fewer than $70 \%$ of patients in the surgical ward were prescribed antibiotics for surgical prophylaxis, and the average number of antibiotic doses administered was 19.1. This is appreciably higher than the WHO and other recommendations, which indicate the use of just one dose administered up to one to two hours before the first incision [55-57]. These findings are a cause of concern because prolonged use of antibiotics for surgical prophylaxis may lead to adverse drug reactions and promote antibiotic resistance. Educational interventions are now required in the hospital to address this and promote more rational use of antibiotics among surgical patients. There is also concern with the high use of third generation cephalosporins in particular ceftriaxone in surgical ward (Figure 3) as ceftriaxone is not indicated for surgical prophylaxis $[55,56,58,59]$. This needs to be investigated further considering that none of the local guidelines advocate for the use ceftriaxone for surgical prophylaxis. This is further supported by the fact that there were no cases of pneumonia, septicemia or meningitis in the surgical ward that could warrant the prescribing of ceftriaxone.

The most commonly prescribed classes of antibiotics were third generation cephalosporins, imidazole derivatives and broad spectrum penicillins (Figure 3), consistent with a published study in Egypt [16]. The high prevalence of use of third generation cephalosporins in the pediatric ward (Figure 3) could be attributed to the fact that pediatric patients tend to have a high prevalence of serious infections such as pneumonia and meningitis compared to adults. The high consumption of third generation cephalosporins in the medical ward could also be explained by the fact that patients admitted to this ward have a high prevalence of infections, with community acquired infections $(55 \%, p<0.001)$ the most common indication for administering antibiotics in the medical ward (Figure 2). The overall widespread use of third generation cephalosporins in the hospital reflects their tendency to be used for empiric management of serious infections, influenced by the fact that clinicians and nurses find their frequency of dosing convenient. They can be administered once or twice a day compared to the first line agents such as benzyl penicillin, which have to be administered every six hours. This needs to be investigated further 
since, as mentioned, local guidelines advocate for the use of third generation cephalosporins as second line for the management of community acquired infections since earlier use of third generation cephalosporins will increase resistance rates [49].

Assessment of total daily doses of the most frequently prescribed oral antibiotics were found to be optimal when compared to those recommended by UK BNF. This shows prescribers are able to use the BNF effectively and keep up to date with prescribing information that is relevant to their clinical practice. In the case of parenteral antibiotics, there is minimal deviation from the prescribed UK BNF daily doses except ceftriaxone. The recommended maximum daily dose of ceftriaxone is $4000 \mathrm{mg}$ while the clinicians prescribed a total daily dose of $6000 \mathrm{mg}$. This is a cause of concern given that ceftriaxone was the most frequently prescribed antibiotic and overdosing leads to increased treatment costs. Consequently, this should also be investigated further, and protocols put in place to enhance earlier de-escalation of intravenous antibiotics to oral.

The most common route of administration was intravenous $(63.1 \%, \mathrm{n}=210)$ with the intramuscular route accounting for $2.7 \%$. Overall, the percentage of encounters with an injectable antibiotic was $65.8 \%$. This was consistent with another study in Democratic Republic of Congo which reported similar findings (68\%) [60]. There might though represent excessive use of parenteral antibiotics in this facility. However, we did not analyze whether parenteral use of the antibiotics was rational or not, which will be the subject of future research. Parenteral antibiotics are generally indicated for unconscious patients, critically ill patients, those who are nil by mouth and those who are vomiting. It has been noted in many studies that prescribers persist in recommending parenteral use even when a patient can take medicines orally. The highest prevalence of parenteral use of antibiotics was in paediatric ward and newborn unit where over $94 \%$ of antibiotics were administered parenterally. These findings are consistent with a study done in Ghana [61]. This could be explained by the fact that most paediatric patients are not cooperative and suffer from serious conditions that warrant parenteral administration. In other settings, paediatric outpatient parenteral treatment with antibiotics is widely practiced [62].

The average duration of prescribed antibiotics was 5.6 days in our study. The current recommended optimal duration of treatment is usually 7-10 days as a short duration of treatment may lead to longer hospital stay and increase resistance to antibiotics. We will be exploring this further in future research.

This is the first point prevalence survey of antibiotic use in Jaramogi Oginga Odinga Teaching and Referral Hospital in Western region of Kenya. The information gained from this survey will help to formulate policies and guidelines in this hospital and wider in Kenya to improve future antibiotic use in hospitals and limit the spread of resistance. This is already happening.

Limitations to this study include the fact that because the nurses strike started in May 2017 and was continuing, many patients were being discharged from the wards during time of survey and bed occupancy was below the usual level. As a result, files for patients in medical, gynecology and postnatal ward were located using the occurrence book and retrieved from the wards and health records department afterwards. Secondly, records for some patients were incomplete. This was managed by asking the attending clinician to clarify any missing information on the patients' records where they could. Some patient records were missing and could not be traced. However, these limitations apply generally to PPS studies. There was also a low number of requests for sensitivity testing perhaps reflecting the time taken for the findings to be analysed and communicated. Despite this, we believe our findings are robust and we also believe this is the first comprehensive PPS study in this part of Kenya and generally among referral hospitals in Kenya. Lastly, universal sampling was also a strength, improving the generalizability of this study. Lastly, this study was able to give some insight into antimicrobial resistance patterns in the Western region of Kenya to guide future practice.

\section{CONCLUSIONS}

The actual dosing of antibiotics seemed appropriate when assessed against current guidance. However, there were areas of concern. There was high prevalence of antibiotic use, although there may be good reasons for this such as prophylaxis for patients with HIVI AIDS and in motherspost delivery. Third 
generation cephalosporins were also extensively used, in particular ceftriaxone, which needs addressing especially for surgical prophylaxis and the management of community acquired infections. Treatment of bacterial infections is also currently mainly empiric, which is a concern given high levels of resistance to certain antibiotics. Finally, surgical wards should be one a key target area of for educational interventions to promote rational antibiotic use given concerns with the length of surgical prophylaxis and current antibiotic use. Future developments should also include the instigation of formularies and antimicrobial stewardship programmes involving all key stakeholder groups including surgeons.

\section{Author contributions}

$\mathrm{CO}$ and SO designed the study, performed data collection and analysis, and wrote and the first draft paper together with FO, MO, ABK and BG. SO and FO also provided technical guidance during the study and directed data analysis and reviewed the paper. BMO, AMK and BG helped produce subsequent drafts as well as providing technical guidance with the analysis. All authors approved the final submission.

\section{Funding}

There was no funding for this study. However, the write up was in part supported by a Newton Institutional Links grant awarded to Margaret Oluka by the Academy of Medical Sciences, through the UK Government's Newton Fund program

\section{Conflict of interest}

The authors declare they have no conflicts of interest.

\section{REFERENCES}

1. Md Rezal RS, Hassali MA, Alrasheedy AA, Saleem F, Md Yusof FA, Godman B. Physicians' knowledge, perceptions and behaviour towards antibiotic prescribing: a systematic review of the literature. Expert review of anti-infective therapy. 2015;13(5):665-80.

2. Laxminarayan R, Matsoso P, Pant S, Brower C, Rottingen JA, Klugman K, et al. Access to effective antimicrobials: a worldwide challenge. Lancet. 2016;387(10014):168-75.

3. Holloway K, Mathai E, Gray A. Surveillance of community antimicrobial use in resourceconstrained settings--experience from five pilot projects. Trop Med Int Health. 2011;16(2):152-61.

4. Hwang TJ, Powers JH, Carpenter D, Kesselheim AS. Accelerating innovation in rapid diagnostics and targeted antibacterials. Nature biotechnology. 2015;33(6):589-90.

5. Akhloufi H, Streefkerk RH, Melles DC, de Steenwinkel JE, Schurink CA, Verkooijen RP, et al. Point prevalence of appropriate antimicrobial therapy in a Dutch university hospital. European journal of clinical microbiology \& infectious diseases. 2015;34(8):1631-7.

6. Podolsky SH, Bud R, Gradmann C, Hobaek B, Kirchhelle C, Mitvedt T, et al. History Teaches Us That Confronting Antibiotic Resistance Requires Stronger Global Collective Action. The Journal of law, medicine \& ethics. 2015;43 Suppl 3:27-32.

7. Godman B, Fadare J, Kibuule D, Irawati L, Mubita M, Ogunleye et al. Initiatives across countries to reduce antibiotic utilization and resistance patterns; impact and implications. Drug Resistance in Bacteria, Fungi, Malaria, and Cancer - Arora, Sajid, \& Kalia Eds Publisher Springer Nature ISBN 978-3319-48682-6 Available at URL: https://purestrathacuk/portal/en/publications/initiatives-across-countriesto-reduce-antibiotic-utilization-and-resistance-patterns(bb445446-fd1d-47b3-8f91def5d9e5e3db)/exporthtml.

8. Chijioke AN, Amadi ES, Ukwandu NCD, Obijuru CE, Ohalete V. Prevalence of Antimicrobial Use in Major Hospitals in Owerri, Nigeria. EC Microbiol. 2016;3(5):522-7.

9. O'Neill J. Securing new drugs for future generations: the pipeline of antibiotics. The review of antimicrobial resistance. Available at URL: https://amr-

review.org/sites/default/files/SECURING\%20NEW\%20DRUGS\%20FOR\%20FUTURE\%20GENERATION S\%20FINAL\%20WEB_0.pdf.

10. Frank U, Kleissle EM, Daschner FD, Leibovici L, Paul M, Andreassen S, et al. Multicentre study of antimicrobial resistance and antibiotic consumption among 6,780 patients with bloodstream infections. European journal of clinical microbiology \& infectious diseases. 2006;25(12):815-7.

11. Gandra S, Barter DM, Laxminarayan R. Economic burden of antibiotic resistance: how much do we really know? Clinical microbiology and infection. 2014;20(10):973-80. 
12. Aldeyab MA, Kearney MP, McElnay JC, Magee FA, Conlon G, Gill D, et al. A point prevalence survey of antibiotic prescriptions: benchmarking and patterns of use. British journal of clinical pharmacology. 2011;71(2):293-6.

13. ECDC. European Surveillance of Antimicrobial Consumption Network (ESAC-Net). Available at URL: http://www.ecdc.europa.eu/en/activities/surveillance/ESAC-Net/Pages/index.aspx

14. Mulwa CN, Osanjo GO, Ndwiga SN, Kaburi AN, Muriuki G. Patterns of Prescribing Practices in Makueni County Refferral Hospital , Kenya. African J Pharmacol Ther. 2015;4(4):161-8.

15. Muyu, GM, Mbakaya C, Makokha A. Assessment of Medicine Use Practices in Mbagathi District Hospital Outpatient Department. East Afr Med J. 2013;90(12):387-95. Available from: https://www.ajol.info/index.php/eamj/article/view/108454/98269

16. Talaat M, Saied T, Kandeel A, El-Ata G, El-Kholy A, Hafez S, Osman A, Razik AM, Ismail G, ElMasry S, Galat R, Yehia M, Amer A, Calfee DP. A Point Prevalence Survey of Antibiotic Use in 18 Hospitals in Egypt. Open access Antibiotics. 2014;3(3):450-60. Available from: http://www.mdpi.com/2079-6382/3/3/450/

17. Xie D, Xiang L, Li R, Hu Q, Luo Qq, Xiong W. A multicenter point-prevalence survey of antibiotic use in 13 Chinese hospitals. J Infect Public Health. 2015;8(1):55-61.

18. Oxford J, Kozlov R. Antibiotic resistance--a call to arms for primary healthcare providers. International journal of clinical practice Supplement. 2013(180):1-3.

19. WHO. World Health Assembly addresses antimicrobial resistance, immunization gaps and malnutrition. Available at UTL: http://www.who.int/mediacentre/news/releases/2015/wha-25-may-2015/en/ 20. WHO. Worldwide country situation analysis: response to antimicrobial resistance. Available at URL: http://www.who.int/drugresistance/documents/situationanalysis/en/ [

21. Wesangula E,GuantaiA, OlukaM. KENYAN NATIONAL ACTION PLAN ON ANTIMICROBIALS. 3rd MURIA Training Workshops and Symposium. Available at URL:

file:///C:/Users/mail/Downloads/Kenyan-NAP-Antimicrobials-EWesangula\%252c-AGuantai\%252cMOluka.pdf.

22. Mendelson M, Matoso M. THE SOUTH AFRICAN ANTIMICROBIAL RESISTANCE STRATEGY FRAMEWORK. AMR CONTROL 2015:54-61.

23. Seale AC, Gordon NC, Islam J, Peacock SJ, Scott JAG. AMR Surveillance in low and middleincome settings - A roadmap for participation in the Global Antimicrobial Surveillance System (GLASS). Wellcome open research. 2017;2:92.

24. Abdula N, Macharia J, Motsoaledi A, Swaminathan S, VijayRaghavan K. National action for global gains in antimicrobial resistance. Lancet. 2016;387(10014):e3-5.

25. Brink AJ, Messina AP, Feldman C, Richards GA, Becker PJ, Goff DA, et al. Antimicrobial stewardship across 47 South African hospitals: an implementation study. The Lancet Infectious diseases. 2016;16(9):1017-25.

26. Magill SS, Edwards JR, Bamberg W, Beldavs ZG, Dumyati G, Kainer MA, et al. Multistate pointprevalence survey of health care-associated infections. N Engl J Med. 2014;370(13):1198-208.

27. Alike VW, Roukens M, De Garde E, Nastch S, Lourens M. Usefulness of quality indicators for antibiotic use: case study for the Netherlands Quality in Practice Usefulness of quality indicators for antibiotic use. International journal for quality in health care. 2016;28(6):838-42.

28. Center for Disease Dynamics, Economics and Policy. The State of the World' S Antibiotics. Washington DC; 2015. Available from: http://thewire.in/wp-content/uploads/2015/09/State-of-the-WorldsAntibiotics_proof_9.11.15-1.pdf

29. Tacconelli E, Carrara E, Savoldi A, Harbarth S, Mendelson M, Monnet DL, et al. Discovery, research, and development of new antibiotics: the WHO priority list of antibiotic-resistant bacteria and tuberculosis. The Lancet Infectious diseases. 2017

30. Apondi OE, Oduor OC, Gye BK, Kipkoech MK. HIGH PREVALENCE OF MULTI-DRUG RESISTANT KLEBSIELLA PNEUMONIAE IN A TERTIARY TEACHING HOSPITAL IN WESTERN KENYA. African journal of infectious diseases. 2016;10(2):89-95.

31. Odhiambo F, Galgalo T, Wences A, Muchemi OM, Kanyina EW, Tonui JC, et al. Antimicrobial resistance: capacity and practices among clinical laboratories in Kenya, 2013. Pan Afr Med J. 2014;19:332.

32. WHO. ANTIMICROBIAL RESISTANCE. Global Report on Surveillance, Available at URL: http://www.euro.who.int/en/health-topics/disease-prevention/antimicrobialresistance/news/news/2014/04/new-report-antibiotic-resistance-a-global-health-threat 
33. Nakwatumbah S, Kibuule D, Godman B, Haakuria V, Kalemeera F, Baker A, et al. Compliance to guidelines for the prescribing of antibiotics in acute infections at Namibia's national referral hospital: a pilot study and the implications. Expert review of anti-infective therapy. 2017;15(7):713-21.

34. Matsitse TB, Helberg E, Meyer JC, Godman B, Massele A, Schellack N. Compliance with the primary health care treatment guidelines and the essential medicines list in the management of sexually transmitted infections in correctional centres in South Africa: findings and implications. Expert review of anti-infective therapy. 2017;15(10):963-72.

35. Ezenduka C, Nworgu C, Godman BB, Massele A, Esimone C. Antimalarial treatment patterns among pregnant women attending antenatal care clinics in south east Nigeria and the future implications. International journal of clinical practice. 2016;70(12):1041-8

36. Afriyie DK, Amponsah SK, Dogbey J, Agyekum K, Kesse S, Truter I, et al. A pilot study evaluating the prescribing of ceftriaxone in hospitals in Ghana: findings and implications. Hospital practice (1995). 2017;45(4):143-9

37. Meyer JC, Schellack N, Stokes J, Lancaster R, Zeeman H, Defty D, et al. Ongoing Initiatives to Improve the Quality and Efficiency of Medicine Use within the Public Healthcare System in South Africa; A Preliminary Study. Frontiers in pharmacology. 2017;8:751

38. Matlala M, Gous AG, Godman B, Meyer JC. Structure and activities of pharmacy and therapeutics committees among public hospitals in South Africa; findings and implications. Expert review of clinical pharmacology. 2017;10(11):1273-80

39. Fadare J, OgunleyeO, EnatoE, GodmanB, Gustafsson LL. Presence and Functionality of Drug and Therapeutics Committees (DTC) in Selected Nigerian Hospitals - Results of a Pilot Study. MURIA Conference PV NCD DU Studies. 2016: 2 (Available at URL: http://muria.nmmu.ac.za/2nd-MURIATraining-Workshop-and-Symposium,-25-27-J)

40. Kariuki S, Winter C, Gelband H, Laximinarayan R. Antibiotic Use and Resistance in Kenya. Health (San Francisco). Nairobi, Kenya; 2011. Available from: http://www.cddep.org/sites/default/files/garp/sitan/pdf/garp-kenya.pdf 41. Open Data. HIV situation in Kenya. 2014. Available at URL: http://blog.opendata.go.ke/hiv-situationin-kenyal

42. Goossens H, Caniaux I, Gross FM, Jalier V, Miller M, Nathwani D, Zarb P. Protocol:Global Point Prevalence Survey of antimicrobial consumption and resistance . 2013. Available from: http://www.globalpps.com/wp-content/uploads/Global-PPS_full_Protocol-English.pdf

43. Massele A, Tiroyakgosi C, Matome M, Desta A, Muller A, Paramadhas BD, et al. Research activities to improve the utilization of antibiotics in Africa. Expert review of pharmacoeconomics\& outcomes research. 2017;17(1):1-4.

44. PARAMADHAS BDA, KGATLWANE J, TIROYAKGOSI C, MATOME M, MASSELE A, GODMAN B, ERIKSEN J, GUSTAFSSON LL. Antibiotic Utilization Studies Using Point Prevalence Survey in Botswana. MURIA 3 2017; 8. Available at URL: http://muria.mandela.ac.za/muria/media/Store/documents/Abstract\%20book\%20\%20MURAI\%203/MURIA3-AbstractBook-July-2017.pdf [ 45. Massele A, Burger J, Kalemeera F, Jande M, Didimalang T, Kalungia AC, et al. Outcome of the second Medicines Utilisation Research in Africa Group meeting to promote sustainable and appropriate medicine use in Africa. Expert review of pharmacoeconomics\& outcomes research. 2017;17(2):149-52.

46. Schellack N, Dlamini N, Meyer JC, Godman B. Point prevalence survey of antimicrobial utilisation in an academic hospital in the Gauteng province, South Africa. MURIA 3 2017; 7. Available at URL: http://muria.mandela.ac.za/muria/media/Store/documents/Abstract\%20book\%20\%20MURAI\%203/MURIA3-AbstractBook-July-2017.pdf.

47. Waithaka N, Jaldesa G, Qureshi Z, Warren C, Ndwiga C, Solomon M et al. National Guidelines for Quality Obstetrics and Perinatal care. Ministry of Health, Kenya, 2004. Page 243-319. Available from: https//:www.k4health.org/sites/default/files/National Guidelines for Quality Obstetrics and Perinatal care.pdf

48. Basic Paediatric protocols. $4^{\text {th }}$ edition. Nairobi, Kenya: Ministry of Health; 2016. 1-62 p. Available from: https://www.tropicalmedicine.ox.ac.uk/_asset/file/basic-paediatric-protocols-2016.pdf 49. Crouch M, Wafula EM, Abinya NO, Karanja JG, Kaseje DC et al. Clinical Guidelines for Management and Referral of Common Conditions at Levels 4-6: Hospitals. Volume III. M C, editor. Ministry of Medical Services and Ministry of Public Health and Sanitation; 2009. Page 69-96 and page 485. Available from: http://apps.who.int/medicinedocs/documents/s21000en/s21000en.pdf 
50. Weist K, Muller A, Monnet D, Ole H. Surveillance of antimicrobial consumption in Europe 2012. Available from: file:///C:/Users/Diego/Downloads/antimicrobial-consumption-europe-surveillance-2011.pdf 51. Robert J, Péan Y, Varon E, Bru JP, Bedos JP, Bertrand X, Lepape A, Stahl JP and Gauzit R. Point prevalence survey of antibiotic use in French hospitals in 2009. J Antimicrob Chemother. 2012;67(4):1020-6.

52. Zarb P, Coignard B, Griskevicieni J, Muller A, Vankerckhoven V, Weist K, Goosens MM , Hopkins H, Catry B, Monnet DL, Goossens H, Suetens C. The European Centre for Disease Prevention and Control ( ECDC ) pilot point prevalence survey of healthcare-associated infections and antimicrobial use. Eurosurveillance. 2012;17(46):1-16. Available from: http://www.eurosurveillance.org/images/dynamic/EE/V17N46/art20316.pdf 53. Hansen S, Sohr D, Piening B, Diaz LP, Gropmann A, Leistner R. Antibiotic usage in German hospitals: results of the second national prevalence stud. J Antimicrob Chemother. 2013;68:2934-9. Available from: http://oxfordjournals.org 54. Mataranyika PA,KibuuleD, Kalemeera F, Kaura H, Godman B, Rennie WT. Liver enzyme elevations in a cohort of HIV/ AIDS patients on first-line antiretroviral therapy in Namibia: findings and implications. Alexandria Journal of Medicine 54 (2018) 49-56

55. WHO. GLOBAL GUIDELINES FOR THE PREVENTION OF SURGICAL SITE INFECTION. 2016. Available at URL: http://apps.who.int/iris/bitstream/10665/250680/1/9789241549882-eng.pdf?ua=1 [ 56. Ban KA, Minei JP, Laronga C, Harbrecht BG, Jensen EH, Fry DE, et al. Executive Summary of the American College of Surgeons/Surgical Infection Society Surgical Site Infection Guidelines-2016 Update. Surgical infections. 2017;18(4):379-82.

57. de Jonge SW, Gans SL, Atema JJ, Solomkin JS, Dellinger PE, Boermeester MA. Timing of preoperative antibiotic prophylaxis in 54,552 patients and the risk of surgical site infection: A systematic review and meta-analysis. Medicine. 2017;96(29):e6903.

58. Opanga SA, Mwang'ombe NJ, Okalebo FA, Godman B, Oluka M, Kuria KAM. DETERMINANTS OF THE EFFECTIVENESS OF ANTIMICROBIAL PROPHYLAXIS AMONG NEUROTRAUMA PATIENTS AT A REFERRAL HOSPITAL IN KENYA: FINDINGS AND IMPLICATIONS. J Infect Dis Preve Med 2017, 5:3 59. Bratzler DW, Houck PM. Antimicrobial Prophylaxis for Surgery: An Advisory Statement from the National Surgical Infection Prevention Project. Clin Infect Dis. 2004;2627(38):1706-15.

60. Wambale JM, lyamba JL, Mathe DM, Kavuo K, Kikuni T. Point prevalence study of antibiotic use in hospitals in Butembo. Int J Med Med Sci. 2016;8(12):133-9.

61. Appiah -Korang Labi, Noah Obeng- Nkrumah, Edmund Tette Nartey et al. Antibiotic use in a tertiary healthcare facility in Ghana: a point prevalence survey. Antimicrobial Resistance and Infection Control (2018) ; 7: 15.

62. Sanjay Patel, Ed Abrahamson. Stephen Goldring et al. Good practice recommendations for paediatric outpatient parenteral antibiotic therapy (p-OPAT) in the UK: a consensus statement. Journal of Antimicrobial Chemotherapy, 2015; Vol 70 (2): 360-373. 